\title{
Assessment Method for Substation Capacity Credit of Generalized Power Source Considering Grid Structure
}

\author{
Wenxia Liu, Yicong Liu *, Shuya Niu and Zongqi Liu \\ State Key Laboratory of Alternate Electrical Power System with Renewable Energy Sources, North China \\ Electric Power University, Beijing, 102206, China; lwxia@ncepu.edu.cn (W.L.); 18701676036@163.com (S.N.); \\ lzq@ncepu.edu.cn (Z.L.) \\ * Correspondence: lycncepu@163.com or 1152201383@ncepu.edu.cn; Tel.: +86-10-6177-2732 \\ Academic Editor: Tomonobu Senjyu \\ Received: 13 April 2017; Accepted: 25 May 2017; Published: 2 June 2017
}

\begin{abstract}
This paper presents the concept of the generalized power source in an active distribution network. After the energy storage system (ESS), distributed generators (DG), and demand-side controllable load are connected to the active distribution network, part of the system load can be undertaken by these ESS, DG, and controllable load instead of relying on the capacity of the substation, which greatly improves the reliability of the system. The above-mentioned distributed energy resources in the active distribution network are collectively referred to as the generalized power source (GPS). Substation credible capacity refers to the capacity of the GPS to supply the distribution network that is equivalent at the high voltage distribution network level when considering the faults of the main transformer, $110 \mathrm{kV}$ lines, and circuit breakers. Considering the uncertainties and control strategies of GPS, this paper takes a specific distribution area as the background to study its substituted substation capacity. Based on a sequential Monte Carlo evaluation framework and the principle of constant reliability, an evaluation method of the GPS credible capacity is proposed. In order to verify the effectiveness of the method proposed in this paper, the credible capacity of various typical connection modes of a high voltage distribution network is quantitatively analyzed in the case study, which can provide a reference for the capacity planning of an active distribution network substation and grid structure selection.
\end{abstract}

Keywords: generalized power source; credible capacity; high-voltage distribution system; grid structure; reliability calculation

\section{Introduction}

An active distribution network can effectively integrate the distributed generation (DG), demand response (DR) load, energy storage, and other resources on the demand side, which can significantly improve the utilization ratio of equipment and the acceptable capacity of green energy [1]. With continuous increases in DG, energy storage system (ESS), and demand response (DR) resource penetration, they can be used to replace the substation capacity to carry part of the load.

Many existing studies only consider the capacity value of DG, while they fail to fully account for energy storage, DR, and its equivalent capacity value when interacting with DG. Therefore, in this paper, distributed generation, energy storage system, and demand-side controllable load are collectively referred to as the generalized power source (GPS) in an active distribution network. At the stage of substation capacity planning, we aimed to integrate the coordinated operation of the DG, ESS and DR, in addition to comprehensively accounting for their capacity value. Evaluating the amount of load that can be undertaken by the generalized power source instead of relying on substation capacity 
in the distribution network is important for substation locating, sizing, and reliability analysis with large-scale GPS integration.

The existing research on substation planning with DG mainly focuses on the calculation of the DG penetration level and the optimal configuration of DG [2,3]. In the substation planning stage, when the DG accesses the grid, there are two traditional methods of processing its influence on the substation locating and sizing. One method regards DG as a dynamic load with negative power consumption. The DG output is multiplied by a certain coefficient and counted in the total installed capacity. Although this method considers the contribution of DG output and effectively reduces the planning capacity of a substation, it does not consider the volatility of DG output. The loss of part of the load caused by potential DG failure will reduce the reliability of the system. The other method only considers the minimum DG output, which is conservative and cannot fully consider the DG capacity value.

At present, domestic and foreign scholars use the concept of credible capacity to evaluate the contribution of DG to maintaining an adequate system capacity. However, most of the studies are at the transmission grid level, which aims to study how much generating capacity can be replaced by DG. The related work is as follows: In a previous study [4], an empirical model for assessing the capacity of large-scale photovoltaic power generation is proposed, in which the capacity credit of a utility-grade photovoltaic was calculated using the effective load carrying capacity (ELCC) method. Another study [5] used the capacity factor method (CF) to measure the capacity credit of wind power instead of ELCC, but this method avoided the reliability calculation model and is not precise enough. Another author [6] extended the concept of power generation credible capacity to energy storage systems and demand-side response resources to assess the alternative to conventional generators.

The research of credible capacity mentioned above has all been undertaken at the transmission grid level. In more recent studies [7,8], the concept of credible capacity has been enlarged to the distribution grid level for the first time. A new substation optimization method based on capacity credit evaluation with DG is proposed. The specific method is as follows: in the intermediate link of the substation planning, the expected energy not supplied (EENS) is selected as an indicator of reliability. The increased load capacity after DG access is studied under the premise of equal generation reliability. This increased load is defined as the capacity credit, and will be deducted from the substation capacity. However, the shortcoming of this substation planning method is that the reliability calculation only takes the generation reliability into account and does not consider the influence of high-voltage distribution network structure. Therefore, the planned substation capacity would not reach the predetermined reliability level. As a result, re-updating the substation capacity according to the DG capacity credit may lead to great differences in transformer capacity and type selection in one area, which cannot guarantee the unity and consistency of the transformer selection in the same region. This method only considers DG and does not fully consider the value of the energy storage, DR, and its interaction with DG. In another study [9], the influence of the controllable load on the smart grid is evaluated by the improvement in power quality and reduction of the network loss in the high photovoltaic (PV) permeability grid.

As mentioned above, most of the studies to-date are at the transmission grid level, which studies how much generating capacity can be replaced by DG. The research gap of the credible capacity is that few studies are at the distribution grid level, with a lack of studies examining how much substation capacity can be replaced by GPS. Meanwhile, the influence of grid structure has not yet been considered. With the increasing access of distributed power supply and the load, the role of GPS should be considered when upgrading the grid. Therefore, the method of integrating the coordinated operation of the GPS and the method to account for the capacity replaced by GPS at the stage of the substation capacity planning will become the important issues for the planning of the distribution network with permeability of high distributed energy resources. Among them, the method of calculating the credible capacity is a key component to examine further. 
On the basis of the above research, this paper first gives the definition of the GPS substation credible capacity in the distribution network. Following this, considering the uncertainties and control strategies of GPS, this paper takes a specific distribution area as the background under the premise of forecasting certain values of GPS penetration and GPS scattered distribution in the planning level year, which is needed to study its substation substitution capacity. Because the reliability of a high-voltage distribution network is not only related to the capacity of substations, but also to the structure of the high-voltage distribution network, the assessment method proposed in this paper regarding GPS substation capacity credit has considered the grid structure. The research results can set up the foundation for follow-up substation locating and sizing or the upgrading of the original substation.

The rest of this paper is organized as follows. Section 2 gives the definition of substation credible capacity of GPS in an active distribution network. The GPS output model is introduced in Section 3. Analysis of typical power supply modes of high voltage distribution network and reliability calculation method is shown in Section 4 . The method for evaluating substation credible capacity of GPS considering grid structure is provided in Section 5. Section 6 is the case study. Finally, Section 7 is devoted to the conclusions.

\section{Definition of Substation Credible Capacity of GPS in an Active Distribution Network}

Large-scale distributed energy resources can be actively adjusted in an active distribution network to increase the power capacity and system reliability [10], which can partly replace the load which is currently provided by a higher-level power supply. However, intermittent DGs have strong randomness and volatility, which are difficult to effectively control. The load that the DG of the same capacity can carry is much smaller than that carried by the higher-level power supply. The energy storage system can stabilize the volatility of the intermittent DG output by setting reasonable operation strategies. The DG load capacity can be improved to a certain extent. The demand side response resource-an important part of the active distribution network—can flexibly change the load power according to the demand of the grid.

In summary, the access of DG, ESS, and the demand-side response load improves the reliability of the system and can be equivalent to a certain substation capacity to carry part of the load. The sources mentioned above are collectively known as the generalized power source (GPS) in a distribution network.

In order to evaluate the capacity value of GPS in a distribution network, the concept of credible capacity is adopted. According to different substitutes, the credible capacity of GPS in an active distribution network is defined as generation credible capacity, substation credible capacity, and feeder credible capacity.

1. Generation credible capacity refers to the capacity of the traditional generating units that can be equivalently replaced by the new energy resources unit at the transmission grid level under the same generation reliability, which can be applied to the power balance of power system planning.

2. Substation credible capacity refers to the capacity that can be equivalently replaced by GPS at the high-voltage distribution grid level, under the premise of obeying the equivalent reliability principle, considering the faults of main transformers, $110 \mathrm{kV}$ lines, and circuit breakers. The substation credible capacity can be applied to the overall planning of substation capacity.

3. Feeder credible capacity refers to the line capacity replaced by the power sources at the distribution network level under the condition of a $10 \mathrm{kV}$ line fault, considering the line power flow constraint and ensuring the reliability of a power supply. The line selection is known, and the calculation result is equivalent to the number of standard lines.

By definition, the substation credible capacity is the alternative part of substation capacity replaced by GPS under an equivalent reliability. The effective load carrying capacity (ELCC) indicator is adopted to assess the substation credible capacity of GPS. 
The reliability at this time refers to the reliability of the high-voltage distribution network supplying power to $10 \mathrm{kV}$ under the random failure of $110 \mathrm{kV}$ lines and transformers. Due to the open-loop operation of a high voltage distribution network when there is in-station transferring and inter-station transferring, the reliability calculation needs to consider the topology change and line overload problem. The load capacity at this time is different from the evaluation of the generation credible capacity. This is because when the reliability is the same, the additional loads carried by the substation are not only related to the contribution of DG, but are also closely related to the load rate. A higher load rate results in a higher credible capacity [7]. Therefore, the definition of ELCC in this paper is the payload capacity under a certain load level.

To remove the contribution of the higher-level power grid, the maximum safety load of the given system should be determined first. The maximum safety load of the distribution network is the maximum load supply capacity in the case where the distribution network in a certain power supply area satisfies the N-1 safety standard under the actual operation. When there is no GPS in the system, the further load increases will result in the load rate exceeding the safety value. When this happens, the higher-level power grid will no longer be able to provide additional load capacity support. From this point, under the premise of the equal system reliability, the newly-added load is completely from the GPS. In addition, all the load and generalized power sources are equivalent to $10 \mathrm{kV}$, although this does not involve the medium voltage feeder.

Figure 1 is a schematic diagram of one power supply partition in one substation, indicating the location of GPS.

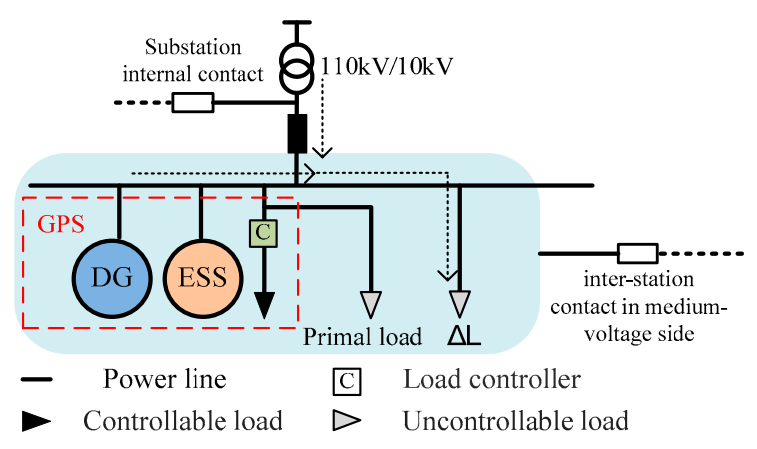

Figure 1. A power supply partition schematic diagram. DG: distributed generation; ESS: energy storage system; GPS: generalized power source.

The substation credible capacity of GPS in an active distribution network can be expressed as Equation (1).

$$
R\left(C_{\mathrm{T}}, L_{0}\right)=R\left(C_{\mathrm{T}}, C_{\mathrm{GPS}}, L_{0}+\Delta L\right)
$$

where $R(\cdot)$ is the high-voltage distribution network reliability estimation function. Its reliability indicator can take LOEE (loss of energy expectation), SAIDI (system average interruption duration indicator) or EENS (expected energy not supplied) into account. Furthermore, $C_{\mathrm{T}}$ is the substation capacity under a certain wiring mode; $C_{\mathrm{GPS}}$ is the accessed GPS capacity under a certain wiring mode; $L_{0}$ is the sum of $10 \mathrm{kV}$ primal loads of substations in the power supply area; and $\Delta L$ is the sum of new load.

When Equation (1) is established, the corresponding $\Delta L$ is the substation credible capacity of $C_{\mathrm{GPS}}$.

\section{GPS Output Model}

In general, there are two types of operation control strategies: cooperative control decision and independent control decision. The control strategy is closely related to the output of each power source. In the cooperative control decision, each DG timing output is related to the control objectives in order 
to smooth the whole output. The optimal output in the independent control decision is related to the control strategy of each DG to maximize the output of a single DG. In this present study, independent control is taken as the example, assuming that GPS operate separately according to each of their own settings below.

\subsection{Distributed Generator Modeling}

Wind turbine generator (WTG) and photovoltaic (PV) are two of the most widely used new energy sources. Therefore, in this paper, DG is represented by WTG and PV, with its sequence output model shown in previous studies [11-13].

\subsection{Energy Storage System Modeling}

The output model of ESS is related to its operation strategy. One of the main tasks of ESS is to smooth the output fluctuation of intermittent energy such as WTG and PV. We defined the difference between load demand and DG output as the net exchange power, $p_{\mathrm{ex}}$. In this paper, the operation strategy of the ESS in the normal running state is set as follows. When $p_{\mathrm{ex}}$ is less than 0 , the energy storage discharges. In comparison, when $p_{\mathrm{ex}}$ is greater or equal to 0 , the excess output power will be used to charge ESS, as described in Equation (2).

$$
\begin{gathered}
p_{\mathrm{BES} . t}^{\mathrm{c}}=\min \left(\eta_{\mathrm{c}}\left|p_{\mathrm{ex}}\right|, \gamma_{\mathrm{c}} S_{\mathrm{nom}}\right), p_{\mathrm{ex}}<0 \\
p_{\mathrm{BES} . t}^{\mathrm{d}}=\min \left(1 / \eta_{\mathrm{d}} p_{\mathrm{ex}}, \gamma_{\mathrm{d}} S_{\mathrm{nom}}\right), p_{\mathrm{ex}} \geq 0
\end{gathered}
$$

where $p_{\mathrm{BES} . t}^{\mathrm{c}}$ and $p_{\mathrm{BES} . t}^{\mathrm{d}}$ are, respectively, charge and discharge power of the energy storage battery at time $t ; \eta_{\mathrm{c}}$ and $\eta_{\mathrm{d}}$ are, respectively, the efficiency of charge and discharge progress; $\gamma_{\mathrm{c}}$ is the ratio between the maximum charge power per unit time and the storage battery rated capacity $\left(S_{\text {nom }}\right)$; and $\gamma_{\mathrm{d}}$ is the ratio between the maximum discharge power per unit time and the storage battery rated capacity $\left(S_{\text {nom }}\right)$.

In order to maintain the fully charged state for ESS in case of a system fault and to reduce the frequency of state change between charge and discharge states to increase the service life of the ESS. This paper states that under normal operating conditions, once the charging starts, the ESS must keep charging until it reaches a specified level. Being different from the normal running state of the system, the net exchange power $p_{\mathrm{ex}}$ in the outage area caused by the fault should be considered as the amount of load transfer, as shown in Equation (3).

$$
p_{\text {ex.t }}=p_{\text {load. } t}+p_{\text {loss.t }}-\sum_{i=1}^{N_{D G}} p_{D G . i . t}-p_{T . t}
$$

where $p_{\text {load.t. }}, p_{\text {loss.t }}$, and $p_{\mathrm{DG} . i . t}$ are, respectively, the total load power in the blackout area at time $t$, grid power loss, and the upload power of Group $i ; p_{\mathrm{T} . t}$ is the amount of load that can be transferred in the power outage area; and $N_{D G}$ is the total number of DGs in the power outage area. The charge and discharge power of the ESS is determined by Equations (2) and (3). In addition, the charge and discharge power and charge state of the ESS should meet the three constraints below [10].

$$
\begin{gathered}
p_{\mathrm{BES} . t}^{\mathrm{c}} \cdot p_{\mathrm{BES} . t}^{\mathrm{d}}=0 \\
S_{\mathrm{oc} . \min } \leq S_{\mathrm{oc} . t} \leq S_{\mathrm{oc} . \max } \\
S_{\text {oc.t }}=S_{\text {oc.t }-1}+\left(\eta_{c} \Delta T p_{B E S . t}^{c}-1 / \eta_{d} \Delta T p_{B E S . t}^{d}\right) / S_{\text {nom }}
\end{gathered}
$$

\subsection{Controllable Load}

The demand-side response based on incentives mainly has the following types: direct load control (DLC), interruptible load (IL), demand side bidding (DSB), emergency demand response (EDR), and 
capacity/ancillary service program (CASP). Load control includes the first two types listed above. In this paper, we used interruptible load as the controllable load. This means that the DLC operators have the ability to shut down or cycle control the users' electrical equipment through remote control devices during the peak period, with the advance notice usually being within $15 \mathrm{~min}$. This paper assumes that the load under the same transformer belongs to the same partition and that when fault occurs, it has a direct control ability related to the controllable load in the same power supply partition and can cut the load down in time if needed.

In this paper, the maximum available controllable load of a single load point is in proportion to the load power of this point, as follows:

$$
p_{\text {D.i.t }}=\alpha \cdot p_{\text {load.i.t }}
$$

where $p_{D . i . t}$ is the controllable load power that can be reduced at time $t$ of load point $i ; \alpha$ is the ratio of the controllable load to the load power of load point $i$; and $p_{\text {load.i.t }}$ is the load power of load point $i$ at time $t$.

The fault recovery mechanism determines the power supply order and the power shortage of the load during the fault process, which ensures the DG power supply is the priority and considers the amount of load that can be transferred. When the two measures are still unable to meet the full load of power in the fault area, the ESS execute the operation fault condition strategy, as shown in Equation (3). The total controllable load to be reduced is as follows:

$$
p_{I L . t}=p_{\text {load.t }}-\sum_{i=1}^{N_{D G}} p_{D G . i . t}-p_{T . t}-p_{B E S . t}^{D}, t \in T_{\text {out }}
$$

where $T_{\text {out }}$ is the outage time. When the total controllable load in that area is greater than $p_{I L . t}$, there will not be a load blackout. On the contrary, when the total controllable load in that area is less than $p_{I L . t}$, this means that part of the load is still not supplied after using all the controllable load to implement direct load control. In this situation, the system power outage load is:

$$
p_{\text {out.t }}=p_{I L . t}-\sum_{i=1}^{N_{D}} p_{D . i . t}
$$

where $N_{D}$ is the total number of controllable load set in the power outage area; and $p_{D . i . t}$ is the controllable load $i$ that can be reduced at time $t$.

\section{Reliability Calculation of High-Voltage Distribution Network Considering Grid Structure}

According to The Code of Planning and Design of Urban Electric Network compiled by State Grid Corporation of China [14], when there is a high-voltage distribution network fault, the power loss loads are first transferred from the high-voltage distribution network, as the load under the same transformer belongs to the same partition. When the fault of the transfer lines or the transferred load reach the upper transfer limit, the power will be transferred through the medium-voltage side between substations. The high-voltage power transfer and the medium-voltage power transfer jointly determine the reliability of the system.

\subsection{Analysis of Typical Power Supply Mode and Transfer Mode of High Voltage Distribution Network}

A high-voltage (HV) distribution network mainly has the following wiring modes: direct power supply wiring, single-sided power T-type wiring, dual-power T-type wiring, and dual-power $\pi$-type wiring. In Figure 2, the electrical wiring diagram of mode 1 [15] — direct power supply wiring mode-is taken as an example. The electrical wiring diagrams of the other three modes are described in Appendix A, and will not be introduced here. Each transformer is responsible for supplying one load partition. 


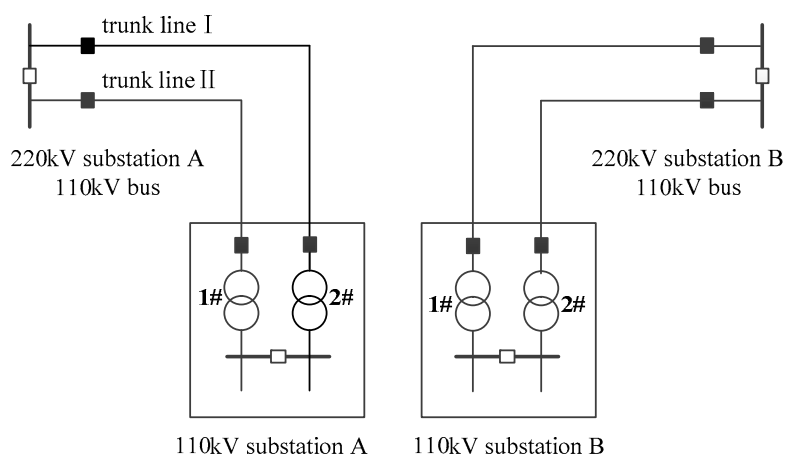

Figure 2. Mode 1, known as the direct power supply wiring.

In this paper, the high-voltage side of the substation uses the line-transformer unit connection mode, whose connection between the incoming line and the main transformer is left out. The low-voltage side uses the sectionalized single-bus configuration. Assuming a transformer capacity of 40 megawatts (MW), there is an inter-station connecting line constraint of $10 \mathrm{MW}$ and a domestic connecting line constraint of $40 \mathrm{MW}$. Each transformer can carry a maximum load of $25 \mathrm{MW}$. As the line limit transmission capacity is generally greater than the sum of the maximum safety load within the transformer substation, the line capacity limit on the transfer load is not considered.

In Figure 2, when the circuit breaker of $110 \mathrm{kV}$ trunk line I fails, the load partition linked to the 2\# transformer of $110 \mathrm{kV}$ substation A loses power. The $25 \mathrm{MW}$ load of this partition will be transferred through the substation A's domestic connecting line and substation B's inter-station connecting line. Since the other three transformers can work properly, the power loss of the area can be transferred from the domestic connecting line for a $15 \mathrm{MW}$ load as well as from the inter-station connecting line for a $10 \mathrm{MW}$ load. The time it takes from blackout to being fully supplied is the load transfer time.

From the above analysis, we can see that the failure treatment approach is different for some components in different wiring patterns, which causes the difference in substation credible capacity after the GPS integration.

\subsection{Reliability Calculation}

At present, the reliability evaluation methods of a distribution network mainly include analytic methods and simulation methods. Considering the time order of PV and sequential control characteristics of ESS, in addition to the random failure of high-voltage lines and transformers, a reliability evaluation method based on a sequential Monte Carlo simulation method is presented in this paper.

The timing model of the active distribution network reliability calculation is established as considering different grid structures. This paper comprehensively considers the expected energy not supplied and loss of energy expectation [16] as the evaluation indicators, as shown in Equation (10) below.

$$
R_{G}=\frac{1}{N}\left(\sum_{n=1}^{q} E_{n s . n}+\sum_{n=1}^{p} E_{n s . n}\right)
$$

where $N$ represents total years of simulation; $E_{n s}$ represents the loss of energy and energy not supplied in one fault condition; $q$ is the GPS component failure status simulation times; and $p$ is circuit component failure state simulation times. Circuit components are the components of the grid other than GPS components. The specific steps are as follows:

Step 1: Generate sequential change sequences. According to the WTG and PV output models, the sequential sequence of WTG and PV are generated in the range of total simulation time $T$. According to the operation strategy under the normal ESS operation states, the state of charge 
(SOC) sequential change sequences of the ESS are generated. The load sequence is constant and is set as the maximum safety load.

Step 2: Generate fault state sequences. Perform sequential simulations of GPS components and circuit components in the system, regardless of double and above failures. When the circuit component fault condition occurs, proceed to step $3 a$ and $p$ plus 1 . When the fault condition of the GPS component is present, proceed to step $3 \mathrm{~b}$ and $q$ plus 1 .

Step 3: Fault evaluation. According to different fault component, the evaluation methods are divided into two types:

(a) When the circuit component fails, look at the failure mode table to determine the loss of load area. Following this, according to the DG output sequence obtained in Step 1, the output condition of DG in the power loss area during the system failure is determined. Determine the size of the load to be transferred and the transfer path: when the transfer fails to complete, conduct a fault operation strategy on the energy storage in the power loss area to supply part of the load. If the total supplement of power for the entire load is not satisfied, determine the quantity of controllable load that needs to be reduced. After all the measures above, the load that still fails to be restored is the dead load of this failure. Record the power shortage for this fault state, $E_{n s . n}$.

(b) When the GPS component fails, determine the fault area and remove the fault power. According to the DG output sequence obtained in Step 1, the output of the remaining DG in the fault area is determined. The rest of the processing is the same as step 3a.

Step 4: Indicator evaluation. The reliability indicator of the system after the GPS integration can be obtained by unifying the GPS component and circuit component fault state calculation indicators, as shown in Equation (10).

\section{Method for Evaluating the Substation Credible Capacity of GPS}

At present, the main methods of credible capacity evaluation are the bisection method $[6,17]$ and Newton method [18]. Considering that there is no specific function formula for derivation, this paper uses the secant method [4,19], which has a fast computing speed. The secant method is a variation of the Newton iteration method, which is a numerical calculation method to find roots. The calculation process is as follows. Take two load values, namely $L_{1}$ and $L_{2}$, with the corresponding reliability values being $R_{1}$ and $R_{2}$. If $R_{1}$ and $R_{2}$ are greater than or less than $R_{0}$ at the same time, these are re-selected until one of $R_{1}$ and $R_{2}$ is greater than $R_{0}$, with the other one being less than $R_{0}$. A straight line connecting the points $\left(L_{1}, R_{1}\right)$ and $\left(L_{2}, R_{2}\right)$, intersect the line whose ordinate is $R_{0}$ and parallel to the abscissa axis at a point $L$. Obtain the corresponding reliability level $R$. If $R$ is greater than $R_{0}, L$ is the new $L_{1}$. Following this, connect the new $\left(L_{1}, R_{1}\right)$ and $\left(L_{2}, R_{2}\right)$ before creating a loop.

The concrete steps of solving the substation credible capacity of GPS in the active distribution network are as follows:

Step 1: Input the grid connection structure of the HV distribution network and the inter-station contact constraint of the substation. According to the previous literature [20], the maximum safety load of the system under the wiring structure is obtained by linear optimization. Through the automatic traversing of the computer, a failure impact analytical table of all circuit components is established and the modes of transferring are determined.

Step 2: Calculate the reliability level $R_{0}$ in the primal system when the GPS is not integrated.

Step 3: Calculate the distribution network reliability level $R_{G}$ with GPS integration using the Monte Carlo simulation method as described in Section 4.2.

Step 4: Using the secant method to adjust load (primal load is the maximum safety load $L_{0}$ ), make the system reliability $R_{G}$ after the GPS integration equal to the primal system reliability $R_{0}$. Obtain the corresponding maximum safety load $L_{\mathrm{p}}$ at this time. The difference between $L_{\mathrm{p}}$ 
and $L_{0}$ is the increment of the load, $\Delta L$, which is exactly the substation credible capacity of the accessed GPS.

The concrete calculation is shown in Figure 3.

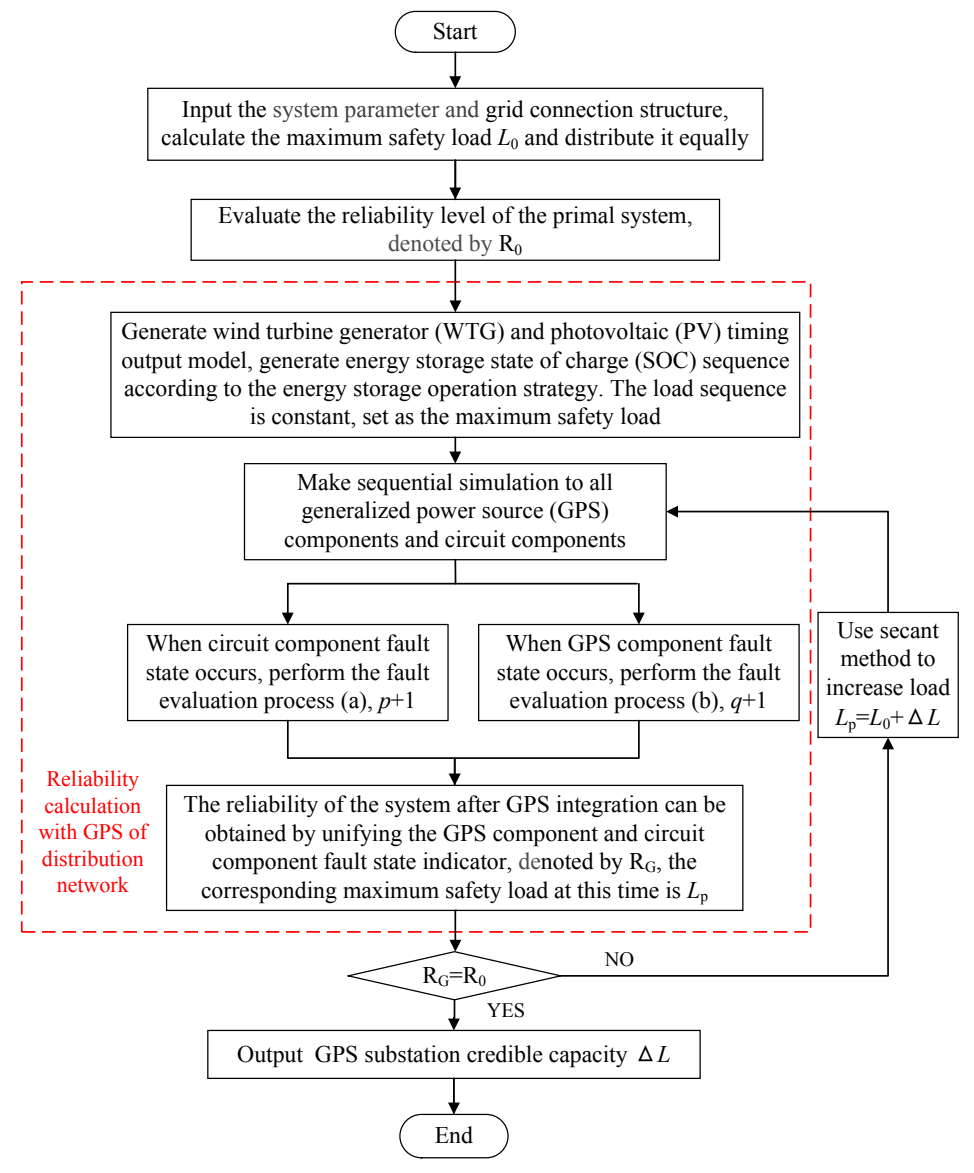

Figure 3. Computation flow of generalized power source (GPS) substation credible capacity calculation.

\section{Case Study}

\subsection{System Parameters}

This paper takes the development zone in Gonghe County of Qinghai as an example. The planning area is $8.41 \mathrm{~km}^{2}$, which is divided into four districts for load forecasting. Supposing that all of the $110 \mathrm{kV} / 10 \mathrm{kV}$ substation capacity in this area are $2 \times 40 \mathrm{MVA}$, the loads in the four districts are equally distributed. The station internal contact constraint is $40 \mathrm{MVA}$, and the inter-station contact constraint is 10 MVA. According to the definition of the maximum safety load, the maximum supply load in one substation partition is 50 MVA. Under normal operating conditions, the peak load that each transformer can take is set as $25.0 \mathrm{MW}$. Therefore, we set the initial annual load peak as $25 \mathrm{MVA}$. If the station internal load transfer is designed with a backup automatic switch, the time for the transfer can be ignored. This paper is confined to the calculation accuracy. In order to make the results more observable, the inter-station load transfer time is set to $1 \mathrm{~h}$. Circuit components are divided into four categories: $110 \mathrm{kV}$ overhead lines, $10 \mathrm{kV}$ circuit breakers, $110 \mathrm{kV}$ circuit breakers, and 110/10 kV transformers. The failure rates and repair time are set in Table 1 , in which $t$ is one time, $a$ represents one year, and $u$ is one component. The reliability parameters of WTG and PV are shown in Table 2. 
Table 1. The component reliability parameters.

\begin{tabular}{ccccc}
\hline Parameter & $\begin{array}{c}\mathbf{1 1 0} \mathbf{~ k V ~ O v e r h e a d ~} \\
\text { Lines }\end{array}$ & $\begin{array}{c}\mathbf{1 0} \mathbf{~ k V} \text { Circuit } \\
\text { Breakers }\end{array}$ & $\begin{array}{c}\text { 110 kV Circuit } \\
\text { Breakers }\end{array}$ & $\begin{array}{c}\mathbf{1 1 0 / 1 0 ~ k V} \\
\text { Transformers }\end{array}$ \\
\hline Failure rate & $0.01 / t \cdot(a \cdot \mathrm{km})^{-1}$ & $0.005 / t \cdot(a \cdot u)^{-1}$ & $0.02 / t \cdot(a \cdot u)^{-1}$ & $0.005 / t \cdot(a \cdot u)^{-1}$ \\
Repair time $(\mathrm{h})$ & 12 & 4 & 7.5 & 48 \\
\hline
\end{tabular}

Table 2. The reliability parameters of wind turbine generator (WTG) and photovoltaic (PV).

\begin{tabular}{ccc}
\hline Parameter & WTG & PV \\
\hline Fault probability $(\% / u)$ & 8.68 & 3.1 \\
Repair time $(\mathrm{h})$ & 5 & 5 \\
\hline
\end{tabular}

In this paper, the case is provided, including four typical connection modes 1 to 4 that respectively corresponded to: direct power supply wiring, single-sided power T-type wiring, dual-power T-type wiring, and dual power supply $\pi$-type wiring. In each mode, a total of four substations of $220 \mathrm{kV}$ and $110 \mathrm{kV}$ are connected in line according to the geographical position in Figure 4 to ensure that the length of line of each mode is substantially equal. ACSR-120/20 overhead line is selected as the $110 \mathrm{kV}$ line.

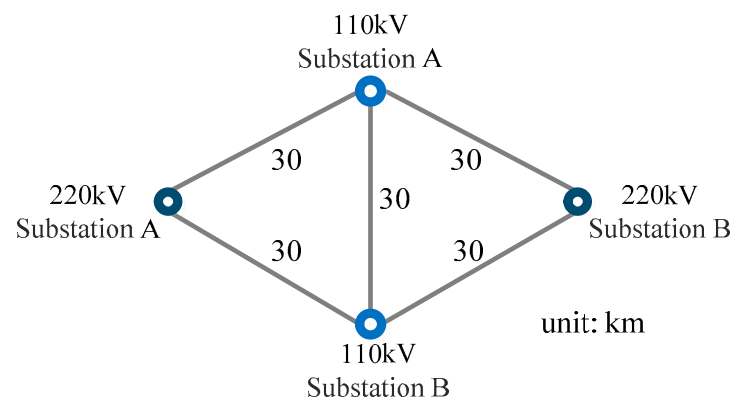

Figure 4. Geographical location sketch map of substations.

On the whole, the failure transfer ways and reliability of the four modes are qualitatively summarized in Table 3.

Table 3. Qualitative analysis of the four modes.

\begin{tabular}{lcc}
\hline & $\begin{array}{c}\text { Transfer Ways When 110 kV Circuit } \\
\text { Breaker on Trunk Line I Fail }\end{array}$ & Reliability \\
\hline mode 1 & In-station + inter-station transfer & - \\
mode 2 & In-station transfer only & Lower than mode 1 \\
mode 3 & Close contralateral breaker, quickly restored & Higher than mode 1 and 2 \\
mode 4 & Isolate the faulty line & Highest \\
\hline
\end{tabular}

The rated installed capacity of photovoltaic power generation in the region is $100 \mathrm{MW}$. The number of wind turbines is 358 units, while the rated capacity is $335 \mathrm{~kW}$. The cut-in wind speed, rated wind speed, and cut-out wind speed of wind turbines are, respectively: $2 \mathrm{~m} / \mathrm{s}, 12 \mathrm{~m} / \mathrm{s}$, and $25 \mathrm{~m} / \mathrm{s}$. According to the data of the Bureau of Meteorology, the average wind speed in Gonghe County is $13.5 \mathrm{~m} / \mathrm{s}$. In addition, a $25 \mathrm{MW}$ load is used as a benchmark for the following GPS penetration rate calculation.

\subsection{Impact of GPS Integration on System Reliability}

This paper comparatively analyzes the trend of distribution network reliability, which was found to vary with the load under both conditions with and without GPS integration. This is shown in 
Figure $5 . R_{0}$ is the reliability without GPS. $R_{G}$ is the reliability with GPS. The expected energy not supplied (EENS) is the indicator of reliability.

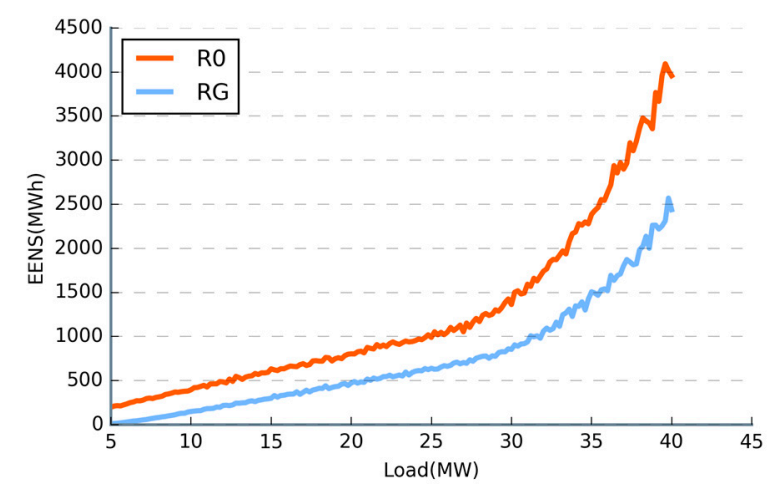

Figure 5. Reliability with and without GPS integration.

With an increase in load, the gap in reliability before and after GPS integration increases, indicating that the credible capacity of GPS increases with load and shows an upward trend. When the load is less than $25 \mathrm{MW}$, the increase in load is not significant, although $\mathrm{R}_{0}$ and $\mathrm{R}_{\mathrm{G}}$ keep following the upward trend. This is because at this time, the load does not reach the maximum safety load of the system. The increased load can be shared by the system line capacity margin and the substation capacity margin, so the power shortage is basically the same. Therefore, in this paper, the initial load capacity corresponding to $\mathrm{R}_{0}$ is set as the maximum capacity of the distribution network satisfying the N-1 constraints, which is the maximum safety load of the system. This aims to eliminate the interference of the system capacity margin.

\subsection{Substation Credible Capacity of GPS under Different Wiring Modes}

During the calculation process, the reliability indicator $\mathrm{R}_{0}$ of mode 2 in the case of no GPS and a load of $25 \mathrm{MW}$ is used as the benchmark to calculate the change of the credible capacity, corresponding to each instance under different GPS penetration rates. At the same time, WTG, PV, ESS, and each power supply penetration iterative calculation step length is $0.5 \%$. In this paper, the definition of GPS penetration rate is defined as the proportion of the sum of the rated capacity of WTG, PV, and ESS to the maximum load of the system. Considering that there is a large influence of the controllable load and that the proportion is small in reality, the controllable load is set as a fixed value of $2 \%$ and is not included in the total penetration. The comparison of the simulation results of the four modes under different GPS penetration rates is shown in Figure 6.

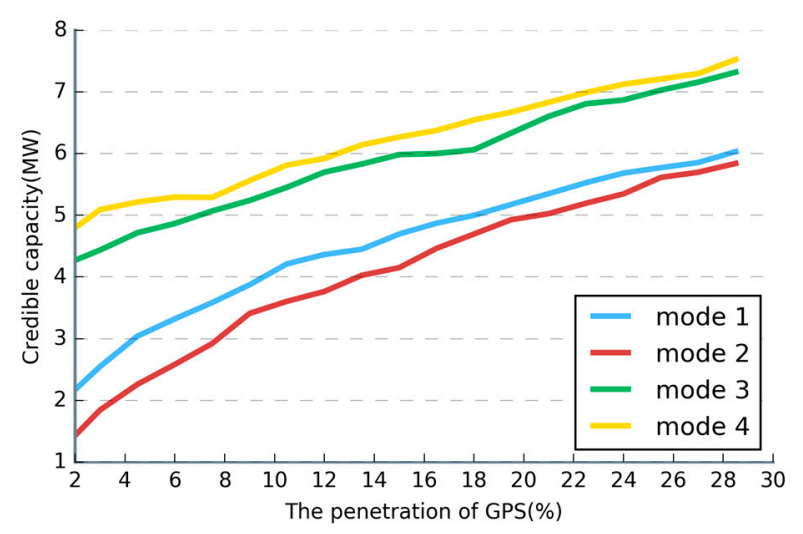

Figure 6. Credible capacity under different wiring modes. 
Comparison between credible capacities of four wiring modes under different GPS penetration rates is shown in Table 4.

Table 4. Credible capacity of the four modes under different GPS penetration (megawatt).

\begin{tabular}{ccccc}
\hline Penetration $\%$ & Mode 1 & Mode 2 & Mode 3 & Mode 4 \\
\hline 2 & 2.3249 & 1.5143 & 4.3188 & 4.8913 \\
4 & 2.9845 & 2.1590 & 4.6632 & 5.1839 \\
6 & 3.3213 & 2.5824 & 4.8665 & 5.2943 \\
8 & 3.7321 & 3.1089 & 5.1240 & 5.3563 \\
10 & 4.1130 & 3.5056 & 5.3889 & 5.8032 \\
12 & 4.3637 & 3.7645 & 5.6991 & 5.9209 \\
14 & 4.5497 & 4.0938 & 5.9010 & 6.1892 \\
16 & 4.7719 & 4.3850 & 5.9933 & 6.3257 \\
18 & 4.9989 & 4.6959 & 6.0621 & 6.5443 \\
20 & 5.2417 & 4.9392 & 6.4457 & 6.7315 \\
22 & 5.4867 & 5.1257 & 6.7352 & 6.9637 \\
24 & 5.6845 & 5.3471 & 6.8693 & 7.1246 \\
26 & 5.7915 & 5.6427 & 7.0727 & 7.2218 \\
28 & 6.0632 & 5.7976 & 7.2695 & 7.4959 \\
\hline
\end{tabular}

According to the results shown in Table 4 and Figure 6, we can see that the substation credible capacity of GPS is different under different grid structures. Among them, the substation credible capacity corresponding to the single-side power T-type wiring in mode 2 is the minimum, while the substation credible capacity corresponding to the two-side power $\pi$-type wiring in mode 4 is the maximum. Mode 2 has the lowest reliability, and mode 4 has highest reliability, which verifies the analysis of Table 3. In addition, with a further increase in penetration, the gaps between substation credible capacities of GPS in those four modes become smaller. Within a certain range, the GPS capacity increases and the improvement of the system reliability is still significant.

\subsection{Substation Credible Capacity of GPS under Different GPS Types}

To further analyze the influence of different types of GPS on the substation credible capacity, we changed the penetration of intermittent DG (WTG and PV), energy storage system (ESS), and the demand-side controllable load (CL). This was made on the basis of other parameters remaining unchanged. Figure 7 shows the corresponding substation credible capacity in different scenarios.

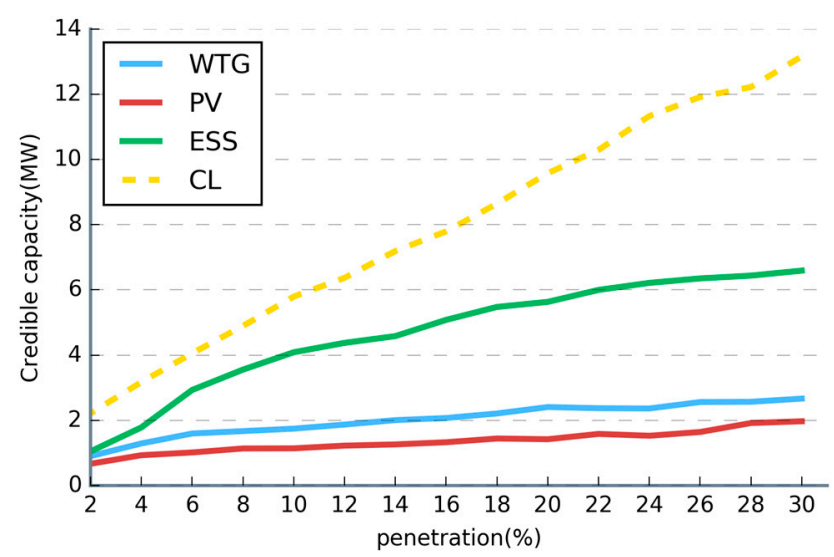

Figure 7. Credible capacity under different types of GPS penetration. CL: controllable load.

As shown in Figure 7, the increase in controllable load penetration contributes the most to the substation credible capacity in the case where only a single GPS increased penetration is considered. 
The impact of ESS is less than that of controllable load. When changing the penetration of WTG or PV power alone, the corresponding variation in substation credible capacity is small. Figure 8 shows the quadratic function fitting for only the changes in WTG and PV penetration. It can be seen that WTG is slightly more pronounced than PV.

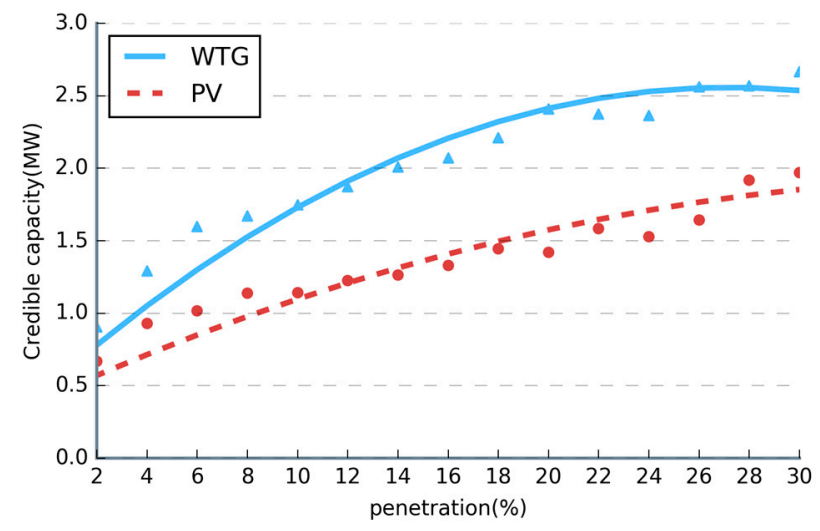

Figure 8. WTG and PV quadratic function fitting curve.

Credible capacity comparison under different DG (WTG and PV) and ESS penetration conditions is shown below (Figure 9).

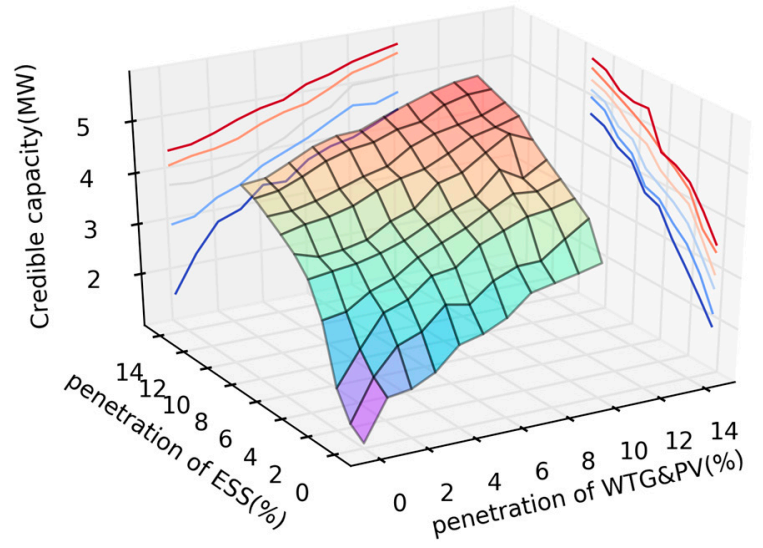

Figure 9. Credible capacity under different DG (WTG and PV) and ESS penetrations.

It can be seen that the increase of controllable load and ESS penetration will significantly improve the reliability of the system and contribute significantly to the substation capacity. Due to the intermittency and fluctuation, the increase of system reliability is not obvious when only WTG or PV is installed. They require ESS for cooperation in order to maximize the reliability of the distribution network and to improve the GPS substation capacity.

\section{Conclusions}

This paper considers WTG, PV, ESS, and the controllable load as a whole, which is referred to as the generalized power source (GPS) in a distribution network. The definition of the substation credible capacity of GPS is provided, and a calculation method of the substation credible capacity considering the grid structure is put forward. The substation credible capacity evaluates the capacity value that GPS can replace the capacity of the substation. The following conclusions are obtained by simulation analysis: 
1. GPS in the distribution network can replace substation capacity. The access of GPS can reduce the shortage of power supply and improve the reliability of the system.

2. It is necessary to consider the influence of the different grid structures on substation credible capacity of GPS in order to improve reliability calculation accuracy and provide reference for the substation capacity planning of GPS integration in an active distribution network.

3. The contribution of the controllable load to substation credible capacity is the most obvious. The influence of the ESS is smaller than that of the controllable load. Due to the intermittency and fluctuation of the PV and WTG, ESS coordination is needed to maximize the substation credible capacity of GPS.

Author Contributions: Wenxia Liu designed, directed and made suggestions to this research. Yicong Liu was responsible for the experiments, analyzed the data and wrote this paper. Shuya Niu contributed to analysis, writing and the revision. Zongqi Liu took part in the revision work. All authors have read and approved the final manuscript.

Conflicts of Interest: The authors declare no conflict of interest.

\section{Abbreviations}

The following abbreviations are used in this manuscript:

$\begin{array}{ll}\text { DG } & \text { Distributed Generator } \\ \text { DR } & \text { Demand response } \\ \text { GPS } & \text { Generalized Power Source } \\ \text { CF } & \text { Capacity factor method } \\ \text { HV } & \text { High Voltage } \\ \text { ESS } & \text { Energy Storage System } \\ \text { CL } & \text { Controllable Load } \\ \text { ELCC } & \text { Effective Load Carrying Capacity } \\ \text { EENS } & \text { Expected energy not supplied } \\ \text { LOEE } & \text { Loss of energy expectation } \\ \text { SAIDI } & \text { System average interruption duration indicator } \\ \text { WTG } & \text { Wind Turbine Generator } \\ \text { PV } & \text { Photovoltaic } \\ \text { DLC } & \text { Direct Load Control } \\ \text { IL } & \text { Interruptible load } \\ \text { DSB } & \text { Demand-side bidding } \\ \text { EDR } & \text { Emergency demand response } \\ \text { CASP } & \text { Capacity/ancillary service program } \\ \text { SOC } & \text { State of Charge } \\ \text { kV } & \text { kilovolt } \\ \text { MW } & \text { Megawatt } \\ \text { MVA } & \text { Megavolt-ampere(s) } \\ \text { ACSR } & \text { Aluminum cable steel reinforced } \\ & \end{array}$

\section{Appendix A}

The electrical wiring diagrams of modes 2, 3, and 4 mentioned in Section 4.1 are respectively shown in Figures A1-A3 [15]. 


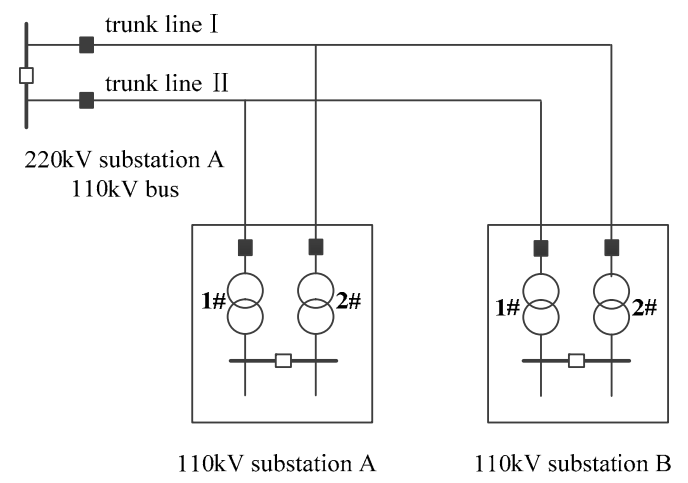

Figure A1. Mode 2, known as single-sided power T-type wiring.

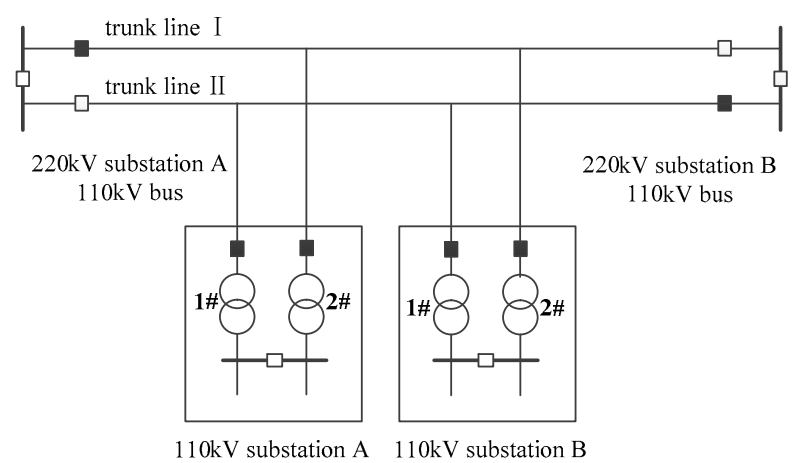

Figure A2. Mode 3, known as dual-power T-type wiring.

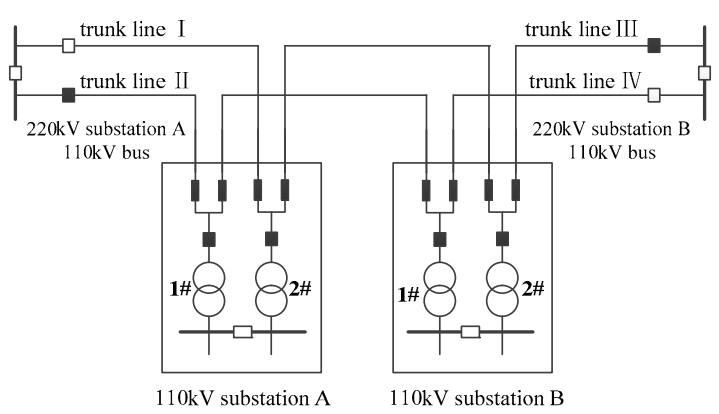

Figure A3. Mode 4, known as dual-power $\pi$-type wiring.

The following is a simple example which illustrates the process of using the Monte Carlo simulation method and the secant method to obtain the GPS substation credible capacity, providing an illustration of the computation flow of Figure 3 in Section 5.

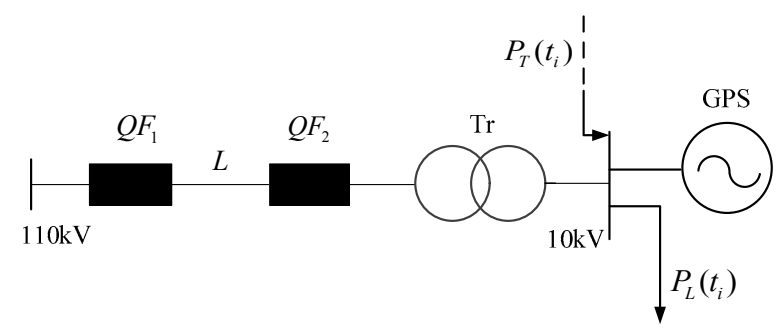

Figure A4. Wiring diagram of the simple example. 
The wiring diagram of the simple example is taken from a portion of the wiring diagram of the direct power supply wiring mode 1 in Figure 2. As shown in Figure A4, there are five components in the network, including non-power components: circuit breakers $Q F_{1}$ and $Q F_{2}$; a transformer $\operatorname{Tr}$ and transmission line $L$; and a generalized power source (GPS) for power supply. These are respectively numbered $j=1,2,3,4,5$. The failure rate of the components is $\lambda_{j}$ in an hour, while the repair time is $\Delta t_{j}$. On the $10 \mathrm{kV}$ bus side, the load $P_{L}\left(t_{i}\right)$ and inter-station transfer power transmitted over the low voltage line $P_{T}\left(t_{i}\right)$ are accessed.

First, the following assumptions are made:

(1) Assuming that there is at most one component failure in the same time period, the probability of a failure of a single component in time $t_{s}$ is satisfied with the Poisson distribution $P_{j}=1-e^{-\lambda_{j} t_{s}}$, where $\lambda_{j}$ represents the failure rate of components in one hour.

(2) To calculate the substation credible capacity of GPS, set $P_{L}\left(t_{i}\right)$ to constant $L_{a}$ here. That is, during the calculation process in $8760 \mathrm{~h}$ of a year, $P_{L}\left(t_{i}\right)$ remains unchanged to remove the impact of load fluctuations.

(3) GPS components only fail in the working state, with the power loss in a failure equal to the rated output of the fault component.

1. The process of obtaining the reliability $R$ using the Monte Carlo simulation method:

(1) Enter the component parameters, set the current time as $t_{i}=0$, the year $k=0$, and the total failure power loss $E_{F}=0$.

(2) Calculate the fault probability $P_{j}$ of the five components.

(3) When $k<\mathrm{N}$ and $t_{i}$ is equal to 8760 , reset $t_{i}=0$. When $k<\mathrm{N}$ and $t_{i}<8760$, calculate the WTG/PV output at time $k$ and determine the SOC status of the ESS according to the size of $P_{W T G}, P_{P V}, P_{L}$, and transfer load $P_{T}$. At time $t_{i}$, five random numbers $(j=1,2,3,4,5)$ that are uniformly distributed are generated. The probability of failure is compared with the corresponding random number.

(4) If $r_{j}>P_{j}$, no failure, return to the third step to calculate the next moment $t_{i}+1$.

(5) If $r_{j} \leq P_{j}$ and $j$ is not a GPS component, $j$ fails and the system switches to the circuit component failure state. The fault lasts for $\Delta t_{j}$ hours.

(i) Calculate the sum of the GPS outputs, including $P_{W T G}, P_{P V}, P_{L}$, and $P_{T}$, and compare with load $P_{L}$ to determine the size of the controllable load $P_{D}$ to be reduced.

(ii) If there is still a load to be supplied after all the controllable load resources are used, the remaining load at this time is the power failure load $P_{f}$. During the time $t_{i}$ to $t_{i}+1$, the total blackout is updated to $E_{F}=E_{F}+P_{f} \times 1$.

(iii) In the event of a fault duration $\Delta t_{j}$, if $t_{i}+\Delta t_{j}<8760$, repeat steps (1) and (2). Otherwise, return to step (3).

(iv) When the fault is over, return to step (3).

(6) If $r_{j} \leq P_{j}$ and $j$ is a GPS component, GPS component $j$ fails, and the system enters the GPS component failure state. The fault lasts for $\Delta t_{j}$ hours.

(i) Calculate the lack of power supply $P_{G}$ for the GPS component.

(ii) During the time $t_{i}$ to $t_{i}+1$, update the total power loss $E_{F}=E_{F}+P_{G} \times 1$.

(iii) In the event of a fault duration $\Delta t_{j}$, if $t_{i}+\Delta t_{j}<8760$, go back to step (6i). Otherwise, return to step (3). After the fault, return to step (3).

(7) When $k=\mathrm{N}$, stop the calculation of the total amount of power loss and calculate the annual average loss of power $\bar{E}_{F}=\frac{1}{N} \times E_{F}$. When $\mathrm{N}$ is large enough, $\mathrm{R} \approx \bar{E}_{F}$ of the system at this time. 
2. Use the secant method to calculate the credible capacity:

(1) Enter the system parameters (including the GPS penetration at this time) and set the initial system maximum power supply load as $L_{0}$.

(2) Use the Monte Carlo method to calculate the original system reliability level $R_{0}$ without GPS.

(3) Calculate the reliability level $R_{G}$ of the system, corresponding to the maximum supply load level under GPS.

(4) Use the secant method to adjust $L_{P}$ and repeat step (3). Finally, make $R_{G}=R_{0}$.

(5) Calculate $\Delta L=L_{P}-L_{0}$ according to the ELCC method, with the substation credible capacity at this level of GPS being $\Delta L$.

\section{References}

1. Liu, W.; Niu, S.; Shi, D.; Xie, J.; Xu, H. Optimal allocation of ADS battery energy storage considering operation strategy and investment subject benefit. Power Syst. Technol. 2015, 10, 2697-2704.

2. Gholizadeh-Roshanagh, R.; Najafi-Ravadanegh, S.; Hosseinian, S. A Framework for Optimal Coordinated Primary-Secondary Planning of Distribution Systems Considering MV Distributed Generation. IEEE Trans. Smart Grid. 2016. [CrossRef]

3. Tanaka, I.; Ohmori, H. Scenario generation with clustering for optimal allocation of renewable DG. In Proceedings of the 2016 IEEE Innovative Smart Grid Technologies-Asia (ISGT-Asia), Melbourne, Australia, 28 November-1 December 2016; pp. 966-971.

4. Ding, M.; Xu, Z. Empirical Model for Capacity Credit Evaluation of Utility-Scale PV Plant. IEEE Trans. Sustain. Energy 2017, 8, 94-103. [CrossRef]

5. Sallam, A.; El-Khattam, W.; El-Salmawy, H. Economic impact of Capacity Credit evaluation for Wind Energy Conversion Systems projects in Egypt. In Proceedings of the Power Systems Conference (MEPCON), 2016 Eighteenth International Middle East, Cairo, Egypt, 27-29 December December 2016; pp. 664-669.

6. Zhou, Y.; Mancarella, P.; Mutale, J. Framework for capacity credit assessment of electrical energy storage and demand response. IET Gener. Transm. Distrib. 2016, 10, 2267-2276. [CrossRef]

7. Ge, S.; Wang, S.; Lu, Z.; Liu, H.; Feng, Z.; Lu, Z. Substation Optimization planning method based on capacity credit evaluation of distributed generator. Autom. Electr. Power Syst. 2015, 19, 61-67.

8. Ge, S.; Wang, S.; Lu, Z. Substation planning method in an active distribution network under low-carbon economy. Mod. Power Syst. Clean Energy 2015, 3, 468-474. [CrossRef]

9. Ziadi, Z.; Taira, S.; Oshiro, M.; Funabashi, T. Optimal power scheduling for smart grids considering controllable loads and high penetration of photovoltaic generation. IEEE Trans. Smart Grid 2014, 5, 2350-2359. [CrossRef]

10. Liu, W.; Niu, S.; $\mathrm{Xu}, \mathrm{H}$. Optimal planning of battery energy storage considering reliability benefit and operation strategy in active distribution system. Mod. Power Syst. Clean Energy 2017, 5, 177-186. [CrossRef]

11. Billinton, R.; Bai, G. Generating capacity adequacy associated with wind energy. IEEE Trans. Energy Convers. 2004, 19, 641-646. [CrossRef]

12. Billinton, R.; Chen, H.; Ghajar, R. Time-series models for reliability evaluation of power systems including wind energy. Microelectron. Reliab. 1996, 36, 1253-1261. [CrossRef]

13. Cha, S.T.; Jeon, D.H. Reliability evaluation of distribution system connected photovoltaic generation considering weather effects. In Proceedings of the 8th International Conference on Probability Methods Applied to Power Systems, Ames, IA, USA, 12-16 September 2004; pp. 451-456.

14. State Grid Corporation of China. The Code of Planning and Design of Urban. Electric Network; China Electric Power Press: Beijing, China, 2007; p. 14, ISBN 155083.1604.

15. Ge, S.; Guo, Y.; Liu, H.; Ma, K.; Liu, J. Load Supply Capability Based Analysis of HV Distribution Network Connection Mode. Power Syst. Technol. 2014, 2, 405-411.

16. Ge, S.; Wang, H. Reliability Evaluation of Distribution Networks Including Distributed Generations Based on System State Transition Sampling. Autom. Electr. Power Syst. 2013, 2, 28-35. 
17. Gami, D.; Sioshansi, R.; Denholm, P. Data Challenges in Estimating the Capacity Value of Solar Photovoltaics. Available online: https://ise.osu.edu/isefaculty/sioshansi/papers/pv_cv_subhour.pdf (accessed on 20 May 2017).

18. Liang, S.; Hu, X.; Zhang, D.; Zhang, H.Y.; Wang, H.H. Capacity credit evaluation of wind generation considering wind speed variation characteristics. Proc. CSEE 2013, 33, 18-26.

19. Zhang, L.; Wu, Y.; Lou, S.; Yang, Y.; Wang, Y. Photovoltaic generation capacity credit evaluation method considering its daily output characteristics. In Proceedings of the 2014 International Conference on Power System Technology, Chengdu, China, 20-22 October 2014; pp. 2763-2768.

20. Chen, K.; Wu, W.; Zhang, B.; Djokic, S.; Harrison, G.P. A method to evaluate total supply capability of distribution systems considering network reconfiguration and daily load curves. IEEE Trans. Power Syst. 2016, 31, 2096-2104. [CrossRef]

(C) 2017 by the authors. Licensee MDPI, Basel, Switzerland. This article is an open access article distributed under the terms and conditions of the Creative Commons Attribution (CC BY) license (http://creativecommons.org/licenses/by/4.0/). 